\title{
8.2. ИССЛЕДОВАНИЕ ПРОБЛЕМ И ВОПРОСОВ УСТОЙЧИВОГО РАЗВИТИЯ В ЗАРУБЕЖНЫХ УНИВЕРСИТЕТАХ
}

\author{
Бурцева К.Ю., к.э.н., доцент, докторант, Департамент «Учет, анализ и аудит»
}

Финансовый университет

при Правительстве РФ, г. Москва

В исследовании рассмотрены подходы зарубежных университетов к устойчивому развитию, включающие цели устойчивого развития для обучения, проведения исследований и вовлечения общества, в Австралии, США и Бразилии. Представлены инициативы Мельбурнского университета по реализации концепции устойчивого развития, инициативы США, включающие в себя работу Ассоциации по продвижению устойчивости в высшем образовании (AASHE), программу STARS, инициативу по мобилизации постшкольных учреждений для решения экологической проблемы изменения климата (ACUPCC). В статье обоснованно, что университеты как места, где происходит большая часть исследований и обучение устойчивому развитию, должны выполнять не только образовательную и научную функции, но и выступать в качестве типовых учреждений - примеров с точки зрения их собственной деятельности. Автором определено, что процессы устойчивого развития организаций, стран и общества следует начинать с создания высококачественного образования, подготовки надлежащих материалов для учащихся, формирования современных подходов к образованию с точки зрения устойчивой перспективы, создания учебных планов, связанных с современными проблемами, установления связи между образовательными программами и реальной жизнью. Проведенный в статье анализ зарубежной практики позволил предложить направления продвижения устойчивости в отечественном высшем образовании: обеспечение соблюдение принципов устойчивости в высшем образовании; содействие институциональным усилиям по интеграции устойчивости в преподавании, исследованиях, взаимодействии с обществом; поддержание всех инфраструктурных функций кампусов в достижении целей устойчивого развития; расширение сотрудничества со всеми группами стейкхолдеров.

\section{Литература}

1. AASHE member directory (Vol. 2015) [Text]. - Philadelphia, PA: Association for the advancement of sustainability in higher education, 2015

2. ACUPCC. Mission and history (Vol. 2015) [Text]. American college \& University presidents' climate commitment, 2015.

3. Brundtland G. Our common future: report of the 1987 world commission on environment and development [Text] / G. Brundtland. - United Nations. 1987.

4. Chambers D.P. Sustainability as a catalyst for changein universities: new roles to meet new challenges [Text] / D.P. Chambers, C. Walker // Davim J.P. Challenges in higher education for sustainability, management and industrial engineering. - Springer international publishing, 2016. - Pp. 1-14.

5. Feriotti M.L. Diversidade, educação cultura e sustentabilidade: relacionando conceitos [Electronic resource] / M.L. Feriotti, D.M.P. Camargo // O Mundo da Saúde. - 2008. - No. 32. - Pp. 359-366. - URL: http://www.saocamilosp.br/pdf/mundo_saude/63/359-366.pdf.

6. Gadotti M. Pedagogia da Terra e cultura de sustentabilidade [Electronic resource] / M. Gadotti // Revista Lusófona de Educação. - 2005. - No. 6. - Pp.15-29. - URL: http://www.scielo.oces.mctes.pt/pdf/rle/n6/n6a02.pdf.

7. Griggs D. et al. Policy: sustainable development goals for people and planet [Text] / D. Griggs, M. Stafford-Smith, O. Gaffney, J. Rockstrom, M. Ohman, P. Shyamsundar et al. // Nature. - 2013. - Pp. 305-307.

8. Howard E. Syracuse university to divest $\$ 1.18$ billion endowment from fossil fuels [Text] / E. Howard // The Guardian. -2015. - Apr. 1.

9. Murga-Menoyo A. La formación de competencias en sostenibilidad: una estrategia para la mejora de la empleabilidad en sociedades sostenibles [Text] / A. Murga-Menoyo, M. Novo // Procedia-Social and behavioral sciences. - 2005. - No. 139. - Pp. 527-535.

10. Resk S.S. Qual é o espaço da educação environmental? [Electronic resource] / S.S. Resk // Revista Fórum. - 2012. - URL: http://www.revistaforum.com.br/blog/2012/06/qual-e-o-espaco-da-educacao-environmental.

11. Robinson J.B. Achieving sustainable development [Text] / J.B. Robinson, A. Dale. - Vancouver: UBC Press, 1996.

12. Routhe A. Reading the signs of sustainability in Christian higher education: symbolic value claims or substantive organizational change? [Text] / A. Routhe // Davim J.P. Challenges in higher education for sustainability, management and industrial engineering. - Springer International Publishing, 2016. - Pp. 15-102.

13. Savageau A. Let's get personal: making sustainability tangible to students [Text] / A. Savageau // International j. of sustainability in higher education. - 2013. - No. 14. - Pp. 15-24.

14. Schmitt J. et al. The Performance of Brazilian government toward sustainability in the context of RIO+20 (United nations conference on sustainable development): an analysis of the Brazilian programs and the importance of education for sustainability [Text] / J. Schmitt et al. // Davim J.P. Challenges in higher education for sustainability, management and industrial engineering. - Springer international publishing, 2016. - Pp. 119-146.

15. STARS. Register for STARS (Vol. 2015) [Text]. - Philadelphia, PA: Association for the advancement of sustainability in higher education, 2015

16. University of Melbourne [Electronic resource]. - URL: https://www.unimelb.edu.au/

17. Vellani F. Institutionalizing ethics of sustainability in American universities [Text] / F. Vellani, N. Nanjee // Davim J.P. Challenges in higher education for sustainability, management and industrial engineering. - Springer international publishing, 2016. - Pp. 147-158.

\section{Ключевые слова}

Университет; развитие; устойчивое развитие; образование; обучение; отчетность об устойчивом развитии.

\section{Бурцева Ксения Юрьевна}




\section{РЕЦЕНЗИЯ}

Современные условия международной глобализации обязывают компании всех отраслей и сфер деятельности адаптировать свою деятельность под быстро изменяющиеся внешние условия путем фундаментальных преобразований внутренних операционных процессов, остро стоит вопрос устойчивого развития организаций. Статья К.Ю. Бурцевой посвящена исследованию проблем и вопросов устойчивого развития в зарубежных университетах и их важности при организации образовательной и научной работы отечественных вузов в целях достижения устойчивости. Актуальность выбранной темы исследования не вызывает сомнения.

По своей структуре и содержанию научная статья полностью соответствует требованиям, предъявляемым к подобным работам. В начале статьи представлено обоснование актуальности темы, сформулирована проблематика, обозначены дискуссионные вопросы. В основу исследования положены труды зарубежных ученых по обозначенной тематике, ресурсы сети Интернет.

Для обоснования своей точки зрения К.Ю. Бурцева изучила опыт развития международных университетов, провела сравнительный анализ данных, выделила преимущества и недостатки деятельности, сделала вывод о наличии проблемных областей достижения устойчивого развития.

В ходе проведенного исследования автор изучила подходы зарубежных университетов к устойчивому развитию, включающие цели устойчивого развития для обучения, проведения исследований и вовлечения общества, в Австралии, США и Бразилии. Научная новизна исследования отражена в предложенных рекомендациях по продвижению устойчивости в отечественном высшем образовании.

Научная статья К. Ю. Бурцевой «Исследование проблем и вопросов устойчивого развития в зарубежных университетах» соответствует всем требованиям, предъявляемым к работам такого рода, и может быть рекомендована к публикации

Никифорова Е.В., д.э.н., професссор, зам. руководителя Департамента учета, анализа и аудита ФГОБУ ВО «Финансовый университет при Правительстве РФ», г. Москва.

DOI 10.38097/AFA.2020.55.95.026 